\title{
PEDAGOGY OF EXTRANEITY: CULTURAL STUDIES IN A GLOBAL INFORMATION AGE
}

\begin{abstract}
The opportunities afforded by technology do not simplify the complexities of learning but instead require "greater" maturity and support for learning (Beaty et al. 2002). Both professional and learning environments have come to recognize the need for the capacity to be innovative (Billet et al. 2017). The development of the actionable epistemic fluency, relational skills, and critical reflexivity that are consequently understood as much needed today could be integrated into cultural studies courses, alongside the field's established theoretical trajectory and reflection on first principles. The latter involves consideration of technical vs. non-technical knowledge as well as conceptual problems of inclusion and relevance. The resultingly interdisciplinary approach to the meaning of the dynamics of contemporary culture has the potential to bring into relief "extraneous" humanistic knowledges and ways of being that are challenged in the information space.
\end{abstract}

Key words: cultural studies, Information Age, critical reflexivity, actionable epistemic fluency, relational skills, networked learning, humanistic knowledges, reflective practice

\section{Introduction}

At the crossroads of displacement, hybridization, and change, students of English, who are now required to take courses in British and American culture, have reason to expect that these courses recognize the problems of inclusion and exclusion highlighted by the tensions of the increasingly globalized and technologically-determined world. Global historian and member of the Max-Planck-Institute Wolf Schäfer, sees the Information Age as inclusionary, noting the inextricably interconnected nature of life "ushered in by a global technoscience, a global economy, a global civilization, and a global environment" at the close of the $20^{\text {th }}$ century. He argues that our global age of information is but one of many to come and that we "must" write "an open-ended and decentered history from the various vantage points of competing cultural perspectives [...] No master narrative is in order" (Schäfer 1995). And yet, pioneer in media and cultural studies and critical theory Henry Giroux has demonstrated exclusionary

*Faculty of Philology, University of Belgrade, Studentski trg 3, 11000 Belgrade, Serbia; e-mail: greta.goetz@ fil.bg.ac.rs 
trends. He cites the continued loss of value for groups of people whose cultural capital differs from that of the dominant class in the hidden curriculum but also the neoliberal dystopian impulses affecting education (Giroux 1983:47-50; 2014). This is to say that the culture of emergence - and emergency, to cite an old prognosis (Taussig 1992) remains. Amidst such indeterminacy, the question may be raised as to what the place and purpose of cultural studies is exactly. Recent trends in the cultural disciplines have sought to bring awareness to competing claims and ideologies and a reassessment of disciplinary bounds ${ }^{1}$. A timeless question that remains unresolved by advances in theory, technology, or globalization remains: What is the human place in all of this? Do we as thinking, feeling individuals have any "say"?

Articulation of the complex global, neoliberal, technological, information age in which we find ourselves necessarily involves skillful self-assembly and relational expertise. This can be developed through epistemic fluency, relational skills, and critical reflexivity which can be made actionable by coordinating concept, context, and actions. Lina Markauskaite and Peter Goodyear (Markauskaite and Goodyear 2017) explain that "Working on real-world problems usually requires the combination of different kinds of specialized and content-dependent knowledge, as well as different ways of knowing". Epistemic fluency is possessed when people are "flexible and adept with respect to different ways of knowing about the world" (Markauskaite and Goodyear 2017: 1). It is "the capacity to understand, switch between and coordinate different ways of knowing with awareness, sensitivity to the situation and skill" that is of central importance here (Markauskaite and Goodyear 2017: 64-5). This knowledge further aids in the accomplishment of things in practical situations - and is therefore described as "actionable". Epistemic fluency is knowledge that "underpins conceptual for understanding, knowledge for action and knowledge entangled in action" (Markauskaite and Goodyear 2017: 89). It is the knowing what and knowing when in practical problem solving (Markauskaite and Goodyear 2017: 95). Accordingly, it involves the relational skills that enable effective work with others, across boundaries

\footnotetext{
${ }^{1}$ The latter is perhaps most clearly outlined by Marc Augé on anthropology, in which he sets out the paradigm for his and others' subsequent work. He has assessed the historical problem of the discipline's move away from its initial evolutionary paradigms and argues for attention to be paid to the new modalities of symbolization (reconfiguring old problems of identity, alterity, and myth) to emerge through the now global information networks. He draws on the tradition of self-criticism in social anthropology to conceive at once world unity and the diversity of worlds that constitute it (2003).

${ }^{2}$ This paper was delivered as part of a panel, also hosting Columbia University's Neni Panourgiá and Eastern Michigan University's Nataša Kovačević, called "Good Sense As Common Sense: The Practice of Cultural Studies Today". The panel sought to address what is needed to safeguard differential experience and ensure that culture works to serve us, and not the other way around, and to ask whether, in the space of community and alterity, what is 'good' is also commonsensical. The author of this paper was also the moderator.
} 
or professions (Markauskaite and Goodyear 2017: 596). Through the assemblage of learning environments a person can begin to see themselves as capable of epistemic action (which is to say sense making) and pragmatic action (Markauskaite and Goodyear 2017: 604). A capacity for critical reflexivity allows for assumptions and practices to be questioned, making problematic issues visible and subject to reflection. It also allows for causes and consequences to be analyzed. These are the capacities that will be addressed here.

Cultural studies, already largely concerned with the dynamics of contemporary culture, which comprises these complex problems and ways of knowing, would be enriched by added focus on these skills (though it has its own tradition of reflexivity). Epistemic fluency is further compatible because it is also concerned with "meaningmaking, seeking through its application to curricula opportunities for students to encounter and reflexively dwell in [...] dynamism and complexity" (Dall'Alba and Barnacle qtd. in Markauskaite and Goodyear 2017: 55, emphasis added). The approach to cultural studies outlined here that will seek to integrate epistemic fluency will take as its starting point the idea that creative cultural understandings likely involve "something more". This view departs from Clifford Geertz's observation in his seminal work on "thick description" that "Cultural analysis is intrinsically incomplete [...] to get somewhere with the matter at hand is to intensify the suspicion, both your own and that of others, that you are not quite getting it right" (Geertz 1973: 322). The critical approach presented in this paper considers the "extraneous", which is to say, that which comes from the outside: the historical, inertextual, rhetorical, "something else", that which is contradictory which may be seen to promote epistemic fluency. It will seek in this way to bring into relief the range and meaning of the actionable potential of the humanistic within the larger collective context of culture. This is also relevant on the individual level, as individuals are implicated in culture.

There is a characteristically humanistic, non-technical, anti-positivist dimension to the medium and conceptual capacity through which we attempt to refine our knowledge. It is also humanistic in terms of the question of its application. To draw on Hans Georg Gadamer's illuminating recapitulation of Aristotelian phronesis

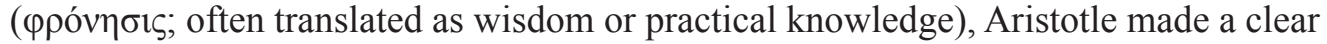
distinction between technical knowledge and moral knowledge. Moral knowledge, which we can describe as the knowledge informing our actions, cannot be knowable in advance like knowledge that can be taught. Its perfect application in an immediate situation requires knowledge of the situation in such a way that one has learned to see the situation as the situation of action in the light of what is right. It involves sympathetic understanding and insight, prepared to consider the particular situation of another person, for example (Gadamer 2004: 318-319). A digression will be made to 
ask: should this not be fundamental to cultural studies? The ability to perceive what is right (even in cultural studies) requires some self-mastery, which can be illustrated by its opposite. This is what happens when one becomes blind to what is right. It is different from being wrong, and is driven by the dialectic of passion (Gadamer 2004: 318-319). Therefore, drawing on Gadamer's reading, we can say that there is a kind of knowledge that cannot be knowable in advance, that requires self-knowledge, and that requires some understanding of the relation between situation, knowledge, and action (as does epistemic fluency). It is noted that situation is external to the individual. Yet a person must relate a text or a subject to their own situation, to apply it to themselves if they want to understand it at all (Gadamer 2004: 319). Application is neither a subsequent nor merely an occasional part of the phenomenon of understanding, but codetermines it as a whole from the beginning (Gadamer 2004: 319). This will be taken as one aspect of a first principle of cultural knowledge: an individual's ability or willingness to relate to a subject codetermines their understanding of it.

Put in terms of Heidegger's reading of Aristotle (Michalski 2005), the activity of conceptual research is not simply an external and more or less incidental circumstance of life, but rather a possibility of existence for which human beings must choose and decide. This is related to the moral knowledge above. But this access to meaning can be obstructed insofar as a person clings "to thinking with an excessive familiarity" not exposing themselves "to the strange that is proper to every originary concept formation" (Michalski 2005: 71). Thinking must attempt to free itself from the idle chatter that obscures meaning (Michalski 2005: 76). Therefore the attempt to reach meaning - central to cultural studies and epistemic fluency, while making use of conceptual discourse not only in terms of its being the appropriate medium for definition and communication but for its being the substance of all scientific research, nonetheless ultimately moves beyond rhetoric because of dialectic: because of the attempt to see what is ultimately meant by the concepts (Michalski 2005: 78). Given that this conceptual knowledge, as seen in the paragraph above, can then be used to inform action, the activity of conceptual research can therefore be seen to come to life.

Discursive practice is therefore of vital importance. A Socratic distinction among types of humanistic discourse would involve the difference between the 'dainty fare' of sophistry and the curative words of philosophy (Plato 1967: 464d). What would a vital approach to cultural studies look like? To depart from an (interdisciplinary) first principle (cf. Aristotle 1929: 8-10), the self is implicated in the degree to which something extraneous is discursively known. This radical approach suggests that we are responsible for how we view cultures especially where our views become judgmental. Yet the exclusionary practice of writing off entire peoples as backward, tribal, or barbaric, as Todorova has shown "Balkanization" to denote (Todorova 1997), 
continues. This is hard to explain given the transformative contribution to the field of cultural studies of Boasian cultural relativism (e.g. Boas 1962).

Alfred Kroeber, who studied under Boas at Columbia University, concisely explains some of the stresses revealed by the cultural relativist approach. For example, it is difficult to reconcile viewing cultures in their own terms with the possibility of ethical absolutes and development or growth. Kroeber viewed cultural relativism as a means to be open to the possibility of learning (without which, one is not understanding the world but predetermining it). It is especially difficult because it is not merely ideatic as our decisions will influence our actions:

Obviously, relativism poses certain problems when from trying merely to understand the world we pass on to taking action in the world: and right decisions are not always easy to find. However, it is also obvious that authoritarians who know the complete answers beforehand will necessarily be intolerant of relativism: they should be, if there is only one truth and that is theirs. (Kroeber 1949: 320)

Being open to a discursive opportunity, to not think with excessive familiarity, will be shown in this paper to be merely an opportunity to reach across external boundaries to a shared space. There are many ways of relating epistemic environments, ranging from deliberative discourse to "juxtaposing tools and practices and jointly inhabiting a material environment" (Goodwin 2005 cited in Markauskate and Goodyear 2017: 61). Underlying these approaches to cultures is Kroeber's proposition that we begin our inquiry with questions, not answers (Kroeber 1949: 320). It will follow that extraneity is a heuristic device that allows for discussion of "cultures" in the broadest sense of the word, considering also the technical vs. the humanistic. The purpose of this is to allow for the fact that technology has been seen to shape and not just be shaped by culture, which is the focus of techno and digital anthropology. It is also to better see our own relational place to better have our sensitively actionable "say" even where the situations in which we find ourselves may appear to be overdetermined by the agendas behind technology or information.

The past century has brought with it the potential to gain a broader historical and cultural perspective. Put another way, different ways of knowing have never been in closer proximity. But both depend on the individual willingness to relate to a subject, which extends beyond the reflexive critical praxis of autoethnography. Put another way: the understanding of a subject - which we know to be one way of knowing among many - that is codetermined by the person understanding it affects the practical, actionable application of this knowledge. This is what we know in a heuristic first principles 
approach. The known unknown is that not all knowledge is necessarily knowable. The unknown unknown is critical because this is ultimately what we are moving towards when we conduct dispassionate inquiry that does not pretend to know the answers. Ultimately, all of us are implicated in our cultural understanding of and consequential actions within the global age of technology and information. This is another way of focusing on the interrelations Boas emphasized as being important to anthropology (Boas 1962: 15).

This approach differs from the discourse of alterity (which itself has a potential dialectic function) in that its purpose is to consider "what else is needed" in the ontoepistemic project of the curriculum (Markauskaite and Goodyear 2017: 55). This extraneous "something else" can involve conscious critical reflection on networks of practice that is conspicuously absent in some academic settings ${ }^{3}$ in addition to historical problems of meaning-making, rhetoric, identity, and professional practice in complex settings. It will be assumed that if the purpose of a university education is indeed liberal - as opposed to being servile, then a diversity of potential avenues, past and present, so potentially "contradictory", be introduced to students as the basis for their own hopefully constructive actions in life. Constructing such epistemic environments that enhance knowledgeable actions requires a "greater" professionalism in teaching in order to cater to differences in how and why people learn as well as to the technological innovations that are being "grafted on" (Beaty et al. 2002).

An attempt will be made to outline the design of epistemic environments that enhance such action below. It takes an inquisitive approach to discursive analysis and deliberation as well as a heuristic models approach ${ }^{4}$ to different ways of knowing, focusing on some that may be considered extraneous to each other. These include history and the present; knowledge and its limits; the geographic as place, non-place, or conceptual paradigm; moral but also technical and scientific culture. The sections consider: intertextualizing dilemmas; history as a deliberative tool; responsible

\footnotetext{
${ }^{3}$ To cite Brown and Duguid's reworking of Jean Lave and Étienne Wenger's "community of practice" (2000). The validity of considering aspects of information technology in connection with cultural studies can be seen in the determinant role information technology is having on society (cf. UC Berkeley's Geoff Nunberg's 2010 iSchool course). That there are differing approaches as to how to integrate such considerations into existing or new disciplines is addressed if cursorily towards the end of this paper Determining the relation of the importance of the Information Age to cultural studies is further important because for all of the latter's discourse of inequality, digital literacy is arguably the source of the greatest gap (see for example Hendrickson et al. 2018). It is further argued by many today that the capacity for learning about knowledge is increasing in the Information Age. For example, see the argument for "augmented knowledge" based on Peter Drucker's prediction of knowledge work being on the verge of effecting major social transformation (Rheingold 1980).

${ }^{4}$ The mental models approach was popularized by Charles Munger, former Vice-Chairman to Warren Buffett's conglomerate Berkshire Hathaway, Inc., in his book Poor Charlie's Almanack (2011).
} 
relational tools; the discourse of place as reaching across external boundaries?; meta tools as cultural unification of (scientific) knowledges? - which builds on the section on responsible tools; recapitulation of these tools in terms of their value for epistemic fluency in a section on relational tools for the collective enterprise, and finally, application of these tools to the present in a section on cultural studies for present emergenc(i)es. A focus of this approach that aligns with more traditional anthropology is its emphasis on ways of being as that which is learned. Most sections explicitly discuss learning. This is because this paper is written with students in mind. It is also because the epistemically fluent actor is one who has learned how to learn as a way of being unto itself, hopefully sensitive to what is worth doing and should be cared for.

This paper does not address the full range of learned human behavior patterns or perceptions (e.g. art, law, and religion) given constraints of length. Where its approach is not explained it is illustrated.

\section{Intertextualizing the dilemma as a tool}

It is one thing for cultural studies to claim to take critically reflexive positions but quite another to develop critically reflexive habits. Heidegger warns of the "idle thought" that can obstruct conceptual discourse from reaching meaningful concepts (Heidegger 1962). American social psychologist and professor of ethical leadership Jonathan Haidt has observed that when faced with difficult issues to think about, people are disinclined to find evidence for their views, relying instead on "pseudo evidence" (Khun cited in Haidt 2006: 64-5). People generally stop thinking once they think they have enough evidence to "make sense" of their position, rather than thinking it through further and considering evidence that opposes their initial positions (Perkins cited in Haidt 2006: 64-5). In this respect then the very practice of considering views beyond the most immediate that come to mind could be considered "extraneous". And the question may be raised as to how to teach "extraneity".

It has been suggested by the GoodWork Toolkit - part of Howard Gardner's Good Project (thegoodproject.org; also cf. Piaget e.g. 1948) - that thoughtful dialogue about inter-human processes begin through consideration of an illustrative dilemma. The dilemma chosen for the opening of this paper is a citation, quoted in full below, in Nikolaj Velimirović's "Nietzsche and Dostoevsky". Velimirović compares Dostoevsky's thoughts with Nietzsche's constructs, which have influenced many of the theoretical orientations in literary and cultural criticism.

While the dilemma to be considered is a direct quote from Brothers Karamazov, Velimirović's work is being referenced here as an example of intertextual "extraneity" to promote deeper thought. Put another way, the specific context of this dilemma models an intertextual approach that effects the kind of "contradiction" Paolo Freire 
recommends. He argues that if we are to take the real action of making our own choices and not be carried along in the wake of the changing times, consideration of contradictions will aid our critical perception (Freire 2005: 6). In the instance presented here, Nietzsche may be taken as exemplary of the changing times. But if Nietzche's is the only approach to morals and what is "good", then his is no longer a theoretical approach, but dogma - which would further be a reductionist reading of Nietzsche, known for his dialectics of provocation. Therefore, it is possible to consider aspects of his ideas in terms of the dilemma presented by Dostoevsky. This is how Velimirovic frames the dilemma. There is validity in performing "extraneous" intertextual work even when already doing the potentially thoughtful work of considering dilemmas. This is also another way of arguing for the cultural importance of being well-read and demonstrating what can be involved in the relational skills of epistemic fluency.

In the context in which we are called to take the real action of making our own choices today, if we have agreed to follow through with Nietzsche the extremes of our logical and scientific philosophy, it will be up to us to forge our own, new morals. But this "new morality" can be seen to take on a sober hue when viewed alongside Dostoevsky's dilemma:

Imagine that you are creating a fabric of human destiny with the object of making men happy in the end, giving them peace and rest at last, but that it was essential and inevitable to torture to death only one tiny creature that baby beating its breast with its fist, for instance - and to found that edifice on its unavenged tears, - would you consent to be the architect on those conditions? (Dostoevsky qtd. in Velimirović 2001: 291)

The dilemma clarifies our perception of the values we hold, the price we are willing to pay for certain goals. The "extraneous" intertextuality surrounding the dilemma clarifies our perception of our willingness to discount or even obliterate a

\footnotetext{
${ }^{5}$ The legitimacy and need for introducing other contexts for comparison is made clear in Lionel Trilling's account of his students who took to the modern literature presented in his course as if it were old hat, not worthy of criticism: "Why do you harry us? Leave us alone. We are not Modern Man. We are the Old People. Ours is the Old Faith. We serve the little Old Gods, the gods of the copybook maxims [...] Leave us alone and let us worship our gods in the way they approve, in peace and unawareness" (Trilling 1961: 32). This legitimacy and need also becomes apparent in the increasingly essentialist landscape designed by algorithms. In response, Jenny Odell asks: "What would a social network look like that [...] would not appropriate but rather accommodate individuals and the not-quite-one, not-quite-two nature of actual interaction and identity? [...] How do you design for patience, for subtlety? Is it possible to build a system that's as alive as we are?" (2018).
} 
way of knowing (an old way of knowing, an other way of knowing, etc.) because it does not seem important to us or is at odds with our theoretical orientation. Ways of knowing can further be discarded because they "limit" the lofty aspirations of our scientific logic to the human realm - with its inherent limitations, interdependence on others, and so on. The consideration of "extraneous" aspects to dilemmas can be the work of cultural studies, which is tasked with giving us the critical tools to make sense of this world and articulate our place in it even where this agency appears to have been denied. Restriction of resources does not change the fact that learning and actionable knowledge are related to the quality of society. Students and teachers who are aware of this bear a greater responsibility.

\section{History as a deliberative tool}

Speaking of responsibility, Lionel Trilling, who was both a teacher and a literary critic, once observed in his role as educator that he felt accountable to the social situation of students and did not have the luxury that the critic has to write for an ideal, uncircumstanced reader (Trilling 1961: 33). In his approach to teaching modern literature, he selected works that would bring conscious awareness to the convictions announced in it. By doing so, he took a critically reflexive approach by bringing a historical context to the convictions that have consequences when embodied in society. His overview included Frazer's validation of the primitive imagination; Freudian discontentment with civilization; the undermining of the commonplace in Tolstoy and Pirandello; Nietzschean Dionysian abandon. Trilling's overview is particularly insightful and is relevant to cultural studies in that it echoes anthropologist Marc Augé's historical account of the Occidental perspective. According to Augé, this gaze has recently turned onto itself, revealing the alterity at the heart of the individual and the crisis affecting inter-human relations in contemporary worlds. Where Augé calls for the self-critical study of anthropology to analyze this crisis in a way that does not cede to a general relativistic abandon (Augé 2003), Trilling uses Matthew Arnold's understanding of a 'timeless modernity' characterized by societal members with mature minds as a counterpoint to the "modern" loss of self and flight from society. Mature minds - like Augé's self-critical approach - are capable of criticism but also of searching for the law of things (Trilling 1961: 22). Self-critical praxis and the Arnoldian view can be seen to be "extraneous" to the aspects of modernity that have been emerging so can be used to bring another, historical perspective to a discussion of what it means to be "modern".

While the potential for historical awareness has never been greater, the legacy of the historical perspective is being threatened. It is ironic that this is happening at the very moment when this wealth could make valuable contributions to negotiating 
the ever closer interconnection of human destinies. Building on an observation made by Erich Auerbach over half a century ago, the human being is more aware than ever of the bigger picture of history and reality: more cognizant than ever of "the view of the structure of inter-human processes" (Auerbach 1969: 10-11). Yet Auerbach also concedes that this breadth of vision is at once threatened by the "leveling" forces of globalization ${ }^{6}$. His view on history has parallels in Nietzsche, who advocated the conscious connection with the past manifest in the "historical sense" although this can be threatened by "mummification" (Nietzsche 1874). The question that could be raised is whether humanity has indeed matured to the level that hindsight of inter-human interaction and processes would seem to afford.

Along these lines, it is assumed here that to be accountable to students in a rapidly changing, conflicted world, some self-critical tradition and understanding of the circumstances and history of cultural development - some perspectives on how different historical ways of knowing and being can change or clash - be conveyed. This is important because they can be used as tools of deliberative consideration of what is good/advantageous, unworthy/disadvantageous (Aristotle 1926: 1.5-6).

Deliberative rhetoric, like the purposes of argument, is to be understood in the Socratic sense as a reasoned "putting forth" of ideas to clarify, reveal alternative approaches, raise ideas, questions, problems, etc. - not a technique to be used for mere persuasion or as an instrument for gaining power or manipulating people. Freedom of choice, which emerges from exposure to different ways of knowing or being, appears to be the greatest achievement of this century. However, as John Dewey, the great educator as well as philosopher and proponent of democracy has written, freedom is best informed (Dewey 1946: 61). Being informed requires receptivity to the past and that which is other.

\section{Responsible relational learning tools}

Keeping with that last idea, we will explore a historical epistemic construct that seeks to relate the individual to the world around them. According to the Stoic theory of appropriation (or oikeí $\omega \sigma / \varsigma$ ), culture begins as something extraneous to the

\footnotetext{
${ }^{6}$ Auerbach writes: "During the past forty years events have enlarged our intellectual perspectives, new outlooks on history and on reality have been revealed, and the view of the structure of inter-human processes has been enriched and renewed. We have participated — indeed, we are still participating — in a practical seminar on world history; accordingly, our insight and our conceptual powers with regard to historical matters have developed considerably" (1969: 10-11). And yet at the same time, he foresees a future marked by a globalization that standardizes and levels - so is counter to an interchange of difference (1969: 2, 7 , 11). This paper seeks to answer his call, in the attempt to reach synthesis, to make people conscious of themselves in their own history - if the objective of earlier epochs to designate the place of humanity in the universe is now too imponderable (1969: 16-17).
} 
individual, who first learns of parents and then community before becoming familiar with the ever more distant rings of culture at large. This will be our model of departure as it corresponds with a GoodWork Toolkit concept (thegoodproject.org) termed "rings of responsibility". It is also a focus of Julia Kristeva's seminal work, L'étrangers à nous-mêmes (Strangers to Ourselves). The continued popularity of this construct can be attributed to the fact that it seeks to build a constructive, coherent view of society, with its members bearing responsibility for their place in society and to each other. It is radical because, drawing on an observation Kristeva has made, the rest of humanity might not necessarily reach this virtue, or wish to (Kristeva 1988: 86).

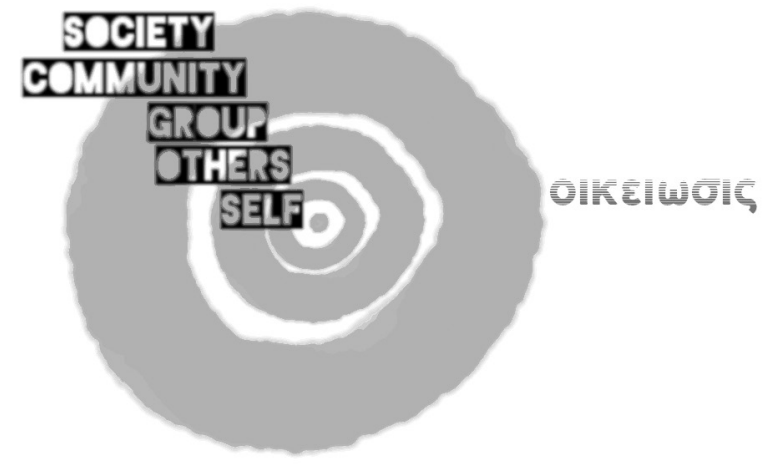

Picture 1. Adapted from The GoodWork Toolkit's "rings of responsibility" (thegoodproject.org)

This view of culture as the appropriation of something that begins as extraneous to us is also comparable to the zone of proximal development attributed to Lev Vygotsky. According to his pedagogical construct, we move through this zone as we appropriate new concepts or skills that are slightly beyond our current abilities through the support of instructional scaffolding (Vygotsky 1979: 86). This can in turn be compared to the relational learning that is central to epistemic fluency. Markauskaite and Goodyear define this as the expertise that allows for interdisciplinary collaboration and communication through the construction of a shared epistemic space, allowing specialized knowledge to be shared and exchanged. They give as an example of this the ability of nurses and pharmacists to communicate with doctors (Markauskaite and Goodyear 2017: 60-61). They also write about "blending" different ways of knowing (Markauskaite and Goodyear 2017:306-7)-which is one way of describing polymathy ${ }^{7}$.

\footnotetext{
${ }^{7}$ It cannot be emphasized enough how relational knowledge is not to "dumb down" existing knowledges, but becomes a "greater" additional task.
} 
In the Viconian humanist view of the suggestively-named university, students were to be exposed to all disciplines (logic to free the mind from false opinion, ethics to master corrupt desires, geometry to check innate errors, etc.) (Vico 1976: 892-4). This idea of assembling, organizing, and committing to memory different fields of knowledge can bring to mind diagrams of the so-called tree of knowledge and those of Francis Bacon and Chrétien Frederic Guillaume Roth (the latter in Diderot and d'Alembert's Encyclopédie). Suffice it to say that a more universal knowledge is achieved through connecting particular (self-limited) branches of learning.

It had once been the goal of Western education to teach students the widest range of subjects. The practical components of ancient Greek paidea ( $\pi \alpha 1 \delta \varepsilon i \alpha)$ included the teaching of not just rhetoric, grammar, and philosophy, but also arithmetic and medicine. Plato's works, which depart from the stipulation that experience is didactic only if we are willing to be taught (Plato 1966: 96a-100d), reveal the epistemic interconnection of subjects as disparate as cosmology and wisdom. More recently, Jorge Luis Borges conceived of an infinite library that was to represent the universe, though it is relevant to note that it may be understood as a warning of intellectual pretension when it becomes too lofty. The parenthetical clauses in this paragraph demonstrate that the tradition of enlarging the bounds of knowledge suggests that this project is bound to be restrained by certain limits. An example of this tradition is Francis Bacon's suggestion that work be guided to be of charitable use (Bacon 2008, 2014).

Mexican architect Antonio Fernández Toca has illustrated Borges' library. The idealistically orderly interconnection of the honeycomb chambers he drew rivals architectural mnemonics of yesteryear (cf. Cicero 1954: 3.16-24) and is closer to Bacon's New Atlantis in which the houses representative of our education seek to enlarge the bounds of knowledge of the human empire:

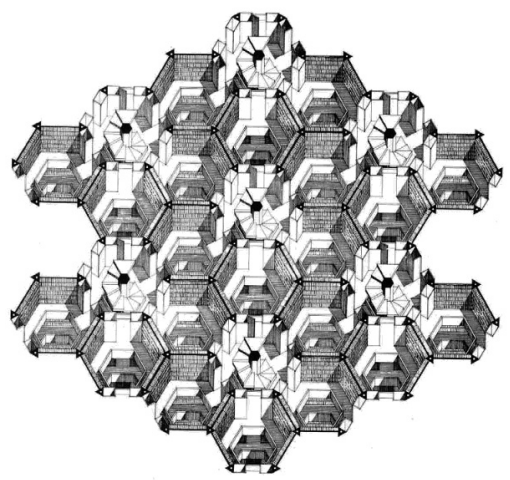

Picture 2. Antonio Toca Fernández (2009: 79) 
For the purposes of introducing the "epistemic fluency" that will be taken in this paper to be one of the goals of contemporary cultural studies, each of those honeycombs could be understood to represent the knowledge of a different (sub-) discipline, all of them interconnected. The diagram could be compared with the charts used to illustrate the complexity theories used to describe the Information Age (e.g. Castellani 2018). It suggests the relational epistemic movement among knowledges.

While Borges expresses a Schäferian sentiment in "Library of Babel" by suggesting that "any one" of the hexagons of this infinite library can be its center (Borges 2013: 2), this paper is also interested in foundational, or axiomatic, models demonstrating organizing and unifying principles articulated from within Western society. In line with the words of Bacon, "We must begin anew from the very foundations, unless we would revolve forever in a circle with mean and contemptible progress" (Bacon 1920: 18). This is not to deny the validity of models that resist organizing principles enjoying popularity today ${ }^{8}$. The consideration of both models is more to speak to the importance of being flexible in our approach to the models used to conceptualize how we think and think with others. For example, the practical application of structurelessness in instruction and governance is both censured and lauded (Freeman and Berzoukov qtd. in Sholler et. al. 2019: Rule 3; Raymond 2000).

The critical point here is that it is not enough to mindlessly repeat knowledge, no matter what system or model is in question ${ }^{9}$. Rather, it is necessary to know how to use it, which is to say to possess the relational skills of epistemic fluency. This is to say that knowing about knowing has become critical to this age and because of its prevalence warrants becoming a focus of cultural studies. For half a century now, it has been argued that the economy of knowledge work would lead to the greatest social transformation (Drucker 1967). There is indeed an increasing demand for knowledgebased transactions. Recognition of this can be seen in fields such as business and management and through the continued popularity of Jean Lave and Étienne Wenger's seminal work that drew on anthropology on communities of practice (Lave and Wenger

\footnotetext{
${ }^{8}$ Example are Foucault's "multiplicities" (2002), the Deleuzian and Guattarian rhizome, or the Deleuzian simulacrum which denies internal resemblance through the relational principle of difference. Interestingly, the Deleuzian and Kraussian vision of simulacrum - meant to define modernity (1983: 55) and departing from Nietzsche - most clearly mirrors the very real marketplace of fake products (watches, purses) in abundance today through the excesses of global capitalism that "defound" originals (see Deleuzian and Kraussian 1983: 53).

${ }^{9}$ See footnote 5 and compare Rudyard Kipling's more positive assessment of the epistemic value of copybook maxims (the problem being that they were learned by rote) in "Gods of the Copybook Headings". He suggests these sayings can be used as timeless safeguards in the brave new world of glitter, markets, and social progress.
} 
2000) in fields such as networked learning. The relational knowledge to emerge from a focus on knowledge work fundamentally encounters problems of how knowledge work is organized. This can be seen in the current focus on variations of systems theory that consider questions such as centralized, decentralized, and distributed systems.

It is interesting that recent work in the field of networked and professional learning is not inclined towards centrally-coordinated networked structures or random, unstructured models but has a preference for "orchestrated" structures sensitive to the needs of context but also aligned with a common purpose (Jackson and Temperley 2007). Such contextually located learning acknowledges that the contexts of experience and learning constantly expand as solutions are sought to complex adaptive challenges (Fullan 2005 cited in Jackson and Temperley 2007). This approach can be seen to correspond with the Stoic theory of appropriation in that it expands as local solutions are sought to enable further learning. Of course, this expansion only makes sense if the direction of growth is deemed good.

\section{Discourse of place: reaching across external boundaries?}

The trajectory of Theory in cultural and literary studies has largely focused attention on the multi-directional movement of culture. Its focus shifts away from any single center, nationality, ius sanguinis, or territorial-based identity. The seminal work to take issue with nationalism is of course Benedict Anderson's Imagined Communities (Anderson 1996), which argues that it is a construct created by the media. Since then, much subsequent literature has been devoted to the existence of "non places" like the airports and supermarkets Augé sees to efface relations, history, and identity (Augé 1995). Arjun Appadurai’s Modernity at Large (Appadurai 2005) addresses the problem of patriotisms that are not fundamentally territorial and are essentially transnational. Where this raises the question of identity (pertinent also to the field of constitutive rhetoric), it does not detract from the larger question of what constitutes moral knowledge. Returning to the first principle taken earlier, we can further ask what this knowledge about our modern communities says about us and who we are.

As noted earlier in this paper, the time in history we occupy has the potential to bring historical awareness. Similarly, the geographical movement of this age has the potential to fuse horizons. The modern individual, exposed to "a permanent and ironic play of similarities and differences, the foreign and the strange, the here and the elsewhere" (Clifford 1988: 146) may identify more with a more "blobby" vision of self, as opposed to the Stoic model of appropriation: 

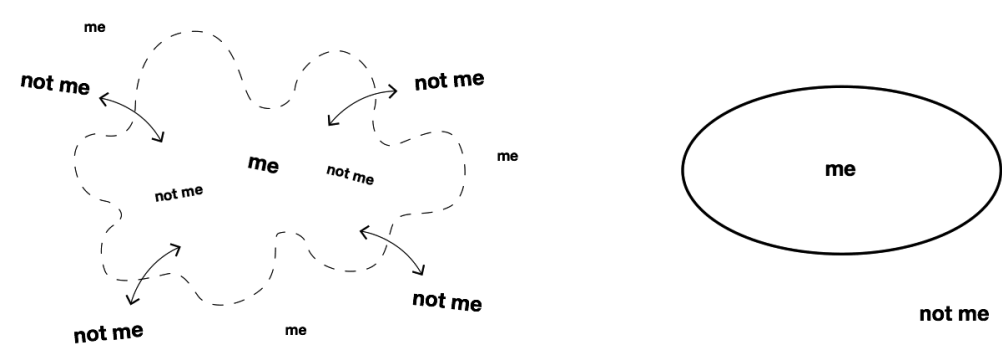

Picture 3. "The blobby self vs. the fortified self" (Odell 2018)

As Bakhtin says of such realities: hybrids emerge (Bakhtin 1998: 291). It is possible to conceive of a historically-established poetic-spiritual model in which the self is seen to be interconnected with the external, transforming the "us" into "them" (Goetz 2008: 121-2). What we are talking about here is internalization of the extraneous, a more elaborate model of the Stoic theory of appropriation. It can begin (aligning with the Stoic theory of appropriation) with something local such as an emotional bond with place. This phenomenon is explained by the emergence of a hybrid field of environment psychology called "place attachment". It could be compared with the older notion of genius loci.

But as discussion of place can also be seen to involve imagination, effacement, identity, patriotism, emotion, and spirituality, it can also be used to promote epistemic fluency. Texts illustrating these different ways of knowing place could be assembled as the basis for informed discussion. Relational skills could be developed by explaining similar aspects of these approaches in terms of one another.

Discussion of place can further involve an us/them binary as well as community, as can be seen in the following two examples. According to the values inherent to ancient Greek paidea ( $\pi \alpha 1 \delta \varepsilon^{\prime} \alpha$ ) and Roman corona civicus, which both value victory of their citizens over the enemy/other, society functions according to an us/them binary. As later iterations of such civic society came to rest on a sensus communis based on Cartesian arbiter and cogito, Gadamer notes that Vico made his own, different appeal to sensus communis, which he based on speaking well (which is our second example). By speaking well he also means speaking the truth: a faculty all men possess, but that is also possessed by the communal sense (Gadamer 2004: 17). This "communal mind", if you will, influences what is available to us (cf. Foucault 2002), what is possible, how we exercise personal responsibility. It influences our "horizon" which in hermeneutics, as in epistemic fluency, we are also to seek to broaden (Gadamer 2004: 
301-5). This broadening represents the ideal of the humanist civic society, in which learning and wisdom is to benefit the human race (Vico 1976: 888): the center of this organizing principle is less on us/other and more on learning. For example, Vico's patriotism is expressed through being initiated into "every form of learning" to be resplendent throughout Europe (Vico 1976: 891). The question can be raised whether this communal sense through learning is being continued in this age, whether it is also founded on speaking well, and whether it, too, includes its own exclusions.

\section{Meta tools: cultural unification through (scientific) knowledges?}

The achievements of $20^{\text {th }}$ century industrialization could be described in terms of research into management science, which beginning from Frederick Winslow Taylor's time and motion study (Taylor 1919) has increasingly sought to improve the output of human work. It is significant to note that a central anecdote in Taylor's study is the question raised to a wage-worker: "Are you a high-priced man?" The importance of the shift seeking to improve human work is critical to a humanistic understanding of the complexity sciences and systems theory to gain prominence in this century.

Seeking to come to terms with the "new globalized society in which we live, as well as the complex set of social problems that come with it" (See Byrne and Callaghan 2014; Capra and Luisi 2014; Castellani and Hafferty 2009; Mitchell 2009), the term "complexity turn" was coined, initially in a 2005 issue of Theory, Culture, and Society (Castellani 2014). Where complexity theory goes wrong and what it can be seen to have in common with Taylor's study, is where it emphasizes functionalism over the idea that society is a complex system (Castellani 2014). The problematic of this approach, even where it uses mixed methods, can be found in the distinction between technical and moral knowledge presented in the incipit to this paper. It is the technical that can be knowable in advance like knowledge that can be taught. What are the pretensions of technical knowledge, the pretensions of management: are they, as Thomas More depicted of idyllic futures, totalizing, totalitarian? (Kristeva 1988: 170)

Julia Kristeva noted three decades ago now that the supra-national unification of commerce and production has made utopia seem possible (Kristeva 1988: 171, 185, 255). Other social unifiers have emerged through the technological advancement of electronic media, including attempts to use AI simulations to econometrics, urban planning, and political science (Spolsky 2019), and some of the motivations behind the "complexity turn". The field of cultural studies has the capacity to address the various epistemic practices that are responsible for the production, economic, technological developments, etc. that shape culture. It should also be stated explicitly that cultural studies should further acknowledge how big data has changed the approaches and 
methodologies in its own field (e.g. Bail 2014). As stated in the 2014 White House report on big data, "What really matters about big data is what it does" (Executive Office of the President 2014: 3). This reminder of the actionable dimension to knowledge has the potential to return us to the question of the moral dimension to knowledge and what the humanities can teach about positivist utopian tendencies. An adumbrated critique of such approaches where they reveal utopic aspirations could invoke the Heideggerian warning of the threat that human (humanistic) "higher essence" can be forgotten when subsumed to the automatic and technical processes humans themselves put in place (Heidegger 1949). The humanities and humanistic can become extraneous to the increasingly controlling motives behind the digital agenda.

But this problem can be approached in another way. John Herman Randall's criticism of utopia clarifies the difference between living in and living by a vision:

There is a constant temptation to live in the vision, rather than by the vision: to want to [...] bring Heaven here to America, like the moderns, instead of using the vision of perfection to discriminate between what is better and what is worse in our relatively and inevitably imperfect world [...] This, it may be, is the truth that lies behind Plato's ironical warning that the effect of poets is often bad: because men are apt to be too stupid to realize that they are poets, and take them literally instead of seriously (Randall 1967: 310).

This question of how to take ideas seriously and not literally also relates to the problem of actionability in epistemic fluency. As the White House report states, what data does is important. But data can only do what we let it. Data is but information: it is we who decide how it informs us.

The question of taking ideas seriously and not literally also comes as a reminder as to the meaning of the Theory that has so characteristically defined the trajectory of cultural studies. Theory is (by definition) not doctrine or "received ideas", though it is sometimes taught as though it is (Myers 1994).

A similar criticism can be made of taking a scientistic view of humanity - and to scientism in general. Scientism is different from science in that it promotes science as the best or only objective approach to epistemic value. Similarly, as stated earlier, scientific (technical) knowledge is in turn different from moral knowledge, as the latter is more elusive in its knowability and is further revelatory of the limits of objectivity (Gadamer 2004). Francis Bacon's works can be seen to illustrate these differences. Bacon, as a scientist, sought to overcome potential obstructions to objectivity, which he termed the "idols of the mind". But despite the fact that he can be seen to have led the 
shift privileging of scientific over philosophical knowledges, his pursuit of scientific knowledge could not be called unchecked. For example, he writes an admonition to individuals in The Great Instauration warning of the lust for power and knowledge ${ }^{10}$. Jacques Barzun has similarly argued for moral deliberation. He notes that by reflecting on historical examples, one becomes aware of "the effect of circumstance, the nature of partisanship, the role of chance, and the influence of leaders and bunglers" - making the student "a better judge of public policy and politicians but also a more tolerant person" (Barzun 1991: 77). Bacon makes this same observation in The Advancement of Learning: learning has the potential to teach people "the force of circumstances, the errors of comparisons, and all the cautions of application [...] And these medicines it conveyeth into men's minds much more forcibly by the quickness and penetration of examples" (Bacon 1913: 15).

Reflection on the moral components of actionable knowledge has been deemed relevant even by scientific minds. While contemporary approaches to science could be termed narrower than it was when it sought, after the Pythagoreans, to decipher or read the book of nature (Hadot 2006: 207-8), there is work being conducted in mechanical physics, for example, that is again cross-disciplinary (e.g. Nagel 2012 or Conn Henry 2005). Astrophysicist Bernard Haisch has demonstrated the "blended" knowledge between consciousness, the universe, and the digital and virtual:

All "data" and every "line of code" would be thoughts. So long as the universe simulation is held in the mind of the fundamental consciousness this creation persists and provides us an arena to play the game of life. And it may ever be a way through which the fundamental consciousness evolves itself: through the actions and life lessons of its projections, i.e. us. (Haisch 2014: 58)

It is not only quantum physics that reaches such essential conclusions. Any work in science that approaches limit questions, the concern with ends, which Ricoeur calls boundary situations, is also bound to be both broad and deep where it searches for meaning. When existence is called into question "the solution $[\ldots]$ is no longer a purely political or technical matter but demands that we ask ourselves the ultimate questions concerning our origins and ends: where do we come from? Where do we

\footnotetext{
${ }^{10}$ This passage is worth citing in full, if in this footnote: "Lastly, I would address one general admonition to all - that they consider what are the true ends of knowledge, and that they seek it not either for pleasure of the mind, or for contention, or for superiority to others, or for profit, or fame, or power, or any of these inferior things, but for the benefit and use of life, and that they perfect and govern it in charity. For it was from lust of power that the angels fell, from lust of knowledge that man fell; but of charity there can be no excess, neither did angel or man ever come in danger by it".
} 
go?" (Ricoeur 1991: 484). An example of an anthropological work that does justice to such scientific work is Stefan Helmreich's "What Was Life? Answers from Three Limit Biologies" (Helmreich 2011).

Therefore, discourse claiming how the sciences gained ascendancy over the humanities could be better informed, as the above illustrations show that it is possible to create an environment for figures or epistemic fields that is shared. It is true that the Baconian division of knowledges inspired William Whewell and Charles Babbage to advocate further specialization of the natural sciences in the $19^{\text {th }}$ century (Snyder 2011: 42 ). It is also true that the scientists of the $20^{\text {th }}$ century no longer had to first read the humanities before being able to study science. But it would be inaccurate to claim that the relationship of these knowledges has led to a definitive victory or that the subject has not continued to be debated (e.g. Arnold 1882, Huxley 1888, Snow 1959, Gould 2003). Yet scientific discourse predominates. Part of the need for relational skills today is the consequence of the increased specialization in scientific fields.

Accordingly, there is a need for what may be termed a hermeneutic receptivity: the ability to acquire the right horizon of inquiry to see where technical or moral knowledge, someone or something else, is coming from, and being willing to continually test one's own prejudices as this horizon is continuously being formed (Gadamer 2004: 302-5).

Helmreich gives an example of a "right horizon of inquiry" when he notes that it was a shared interest in limits that led him to study the biologists he did (Helmreich

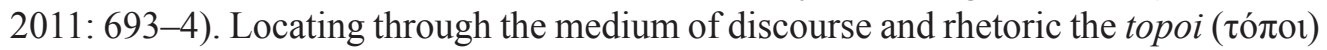
or 'places' where meaning lies requires asking what Gadamer calls "open questions" (Gadamer 2004: 357-8). And this can be difficult, as being open can lead to unexpected conclusions. Richard Conn Henry describes this rather compellingly:

The illusion of matter, which is to say the illusion of a really existing world, is so strong that I think most scientists are unable to overcome it. It took me decades to finally realize that this is not a joke and that the universe is purely mental: that mind is fundamental, matter merely an illusion - and that this is physics, not philosophy (or religion) (Henry 2005: 29).

The ultimate question that will be raised by life whether we address it or not is whether we possess the necessary imagination to conceive meaningfully constructive terms of co-relation in the contemporary world of science and technology. As Ricoeur explains, while understanding is dependent on the capacity of each discipline to realize their independent claims, it is imagination that opens the path towards future possibility: 
Language has lost its original unity. Today it is fragmented not only geographically into different communities but functionally into different disciplines - mathematical, historical, scientific, legal, psychoanalytics, etc. It is the function of a philosophy of language to recognize the specific nature of these disciplines and thereby assign each "language game" its due (as Wittgenstein would have it), limiting and correcting their mutual claims. Thus one of the main purposes of hermeneutics is to refer to the different uses of language to different regions of being - natural, scientific, fictional, etc. But this is not all. Hermeneutics is also concerned with the permanent spirit of language [by which we intend] the capacity of language to open new worlds. Poetry and myth are not just nostalgia for some forgotten world. They constitute a disclosure of unprecedented worlds, an opening on to other possible worlds which transcend the established limits of our actual world. (Ricoeur 1991: 489-90)

This is to say that different epistemologies can be viewed as language games, each potentially opening unprecedented new worlds. While the conceptual domain of epistemologies has become fragmented through dialectic or technical capacities, the philosophy of language has the capacity to reunite these different ways of being. But the philosophy of language (the conceptualization of language: using language to mediate on the way of being that is language) has the further task to keep the linguistic realm of imaginative possibility alive. This is only possible if it is possible to disclose a variety of worlds and ways of being to live by and in. In other words, what may appear to be extraneous can be essential.

Linguistic flexibility, the capacity to see an epistemology or world as being but one of many on the conceptual level of discourse, is also helpful in resolving profound differences of theory. Dewey explains that while the elements of a problem appear to be contradictory, solution comes from departing from the respective fixed meanings of the terms and viewing the problem from a freshly external point of view. This requires "travail of thought" (Dewey 1920: 7).

There is ample common ground for a shared language between the sciences and humanities providing there is a willingness for "travail of thought", to perform "extraneous" sympathetic and imaginative acts. Literary critic and professor Guy Davenport suggested decades ago now that scientific works be read in literature classes in order to teach students to see the actual world with more precision (Davenport 2005: 234-9). This same point is made by Ezra Pound in what is popularly known as his Parable of the Sunfish. The anecdote relates the teaching style of scientist Luis Agassiz who asks a student to describe a fish and rejects every description until the student 
observes it weeks into its decomposition (Pound 1960: 17-18). Pound's introduction to this anecdote is exemplary of the "extraneous" in that he suggests students of poetry continually compare "one "slide" or specimen with another, which may be compared with the suggestion at the beginning of this paper that students compare one text with another. Pound goes so far as to suggest that "No man is equipped for modern thinking until he has understood the anecdote of Agassiz and the fish" (Pound 1960: 17). Humanistic knowledges - which draw on reading and literature, which some would have entirely replaced by "news" - are well-equipped to deal with the determinant and superficially unifying role information technology currently exerts on society. Through the relational epistemic approaches described here, meaning can be sought behind the appearance of phenomena.

It is, after all, a task of cultural studies to be hermeneutically receptive. As Dewey posited, there is perhaps no better definition of culture than its capacity for constantly expanding the range and accuracy of one's perception of meanings (Dewey 1916: 145).

\section{To recap: relational tools for the collective enterprise}

The potential of cultural studies to teach practical or actionable epistemic fluency extends beyond its potential at its rudimentary level to cultivate more "tolerant persons" (as per Barzun 1991) through the awareness of limitations and difference. The study of culture involves some study of science, politics, economics, religion, etc. - so includes the Baconian houses of knowledge together with humanities disciplines, if from the perspective of the latter. The study of culture is an ideal discipline in which to develop interdisciplinary and relational skills, which "goes beyond the self-assembling implied in the performative accounts of learning, to include assembling dynamically a shared [not diluted] material and epistemic space in ways that enable mutual understanding" (Markauskaite and Goodyear 2017: 60-61). It is also conducive to the relational dialogue and critical reflexivity that Beaty et al. (Beaty et al. 2002) have highlighted as being particularly important to networked, or electronically-enhanced, learning, and which are particularly meaningful in societies largely determined by information technology.

While the scientific has been increasingly privileged since Bacon, it is humanists, after all, who are trained in cultural interpretation and critique and can "apply their methods of close reading, historical perspective, social engagement, and linguistic attentiveness to new technologies" (Davidson 2010: 217). Thus as the "culture" of today now (largely) includes online cultures, it stands to follow that some modeling be provided by cultural studies courses in relational skills and how to engage critically and dialogically with online culture (some modeling of effective actionable 
professionalism) - as well as some critique of the medium through which these cultures (whether "real" or "fake" - i.e. engineered ${ }^{11}$ ) have their say.

This approach to contemporary culture can include contrastive historical synthesis, the concepts of literature (in its broadest meaning) and art, Silicon Valley jargon, business strategies, and students' views of the same. It draws on theories of epistemic fluency (Markauskaite and Goodyear 2017), history (cf. Trilling 1961), literary philology (cf. the cultural synthesis implied by Auerbach's Ansatzpunkt 1969), hermeneutic receptivity (cf. Gadamer 2004), media studies (e.g. where it explores medium as a means of communication, cf. Mitchell et al. 2004), as well as some of the Theory that still dominates cultural studies today by continuing the criticism of commodification and globalization by extending a line from Paul Ricoeur via Geertz via Roland Barthes in terms of how culture can be "read". There is a need in the present for the application of such interpretative facilities to present emergenc(i)es.

\section{Cultural studies for present emergenc(i)es}

Threats to "Freedom of belief and conscience, of expression of opinion, of assembly for discussion and conference, of the press as an organ of communication" (Dewey 1946: 61) are largely online today. They include the echo chambers and epistemic bubbles that emerge when we choose, or are led by algorithms, to discredit views that differ and be exposed exclusively to views we already espouse (Nguyen 2018); surveillance capitalism which nonconsensually mines data about us for the purpose of profit (Zuboff 2019); counterfeit capitalism which devalues the price of work by underpricing (Stoller 2019); the engineering of political content on social platforms (Kreiss and Mcgregor 2019), and other forms of networked concealment and bondage. This has the potential to become what Taussig called a "Nervous System", where it rapidly confounds order with disorder, disorder with order in a state of emergency (Taussig 1992) ${ }^{12}$. In such an environment, Vico's simple directive that we should strive to "talk well" and speak the truth is worth remembering though it is further complicated by the fact that this truth is limited by what we perceive it to be at a given time. We remember that the rings of appropriation are always expanding - and can now be understood to be overlapping. Cultural studies, largely concerned

\footnotetext{
${ }^{11}$ By "fake" is meant attempts to dominate nature through excessive engineering of resources. Bacon foresaw this eventuality when he wrote: "And all depends on keeping the eye steadily fixed upon the facts of nature and so receiving their images simply as they are. For God forbid that we should give out a dream of our own imagination for a pattern of the world; rather may he graciously grant to us to write an apocalypse or true vision of the footsteps of the Creator imprinted on his creatures" (2014). A practical example of this would be illustrated by the critique generated by the "counterfeit" "tech" business WeWork (Stoller 2019). ${ }^{12}$ Zygmunt Bauman's prognosis, which he terms "liquid modernity", addresses a "growing conviction that change is the only permanence and uncertainty the only certainty" (2012: Foreword).
} 
with the themes of the time, could benefit from an added focus on actionable relational epistemic skills as well as critical reflexivity, which has been defined in this paper as necessarily including consideration of the historical and "extraneous" in order to deliberate upon the wake of change and better inform freedom of choice.

It bears repeating that the inability to perceive critically current themes, such as new forms of concealment and bondage, is what Freire explains to produce the dangers of any age. As a result, people are carried along in the wake of the changing times, so submerged in it they cannot see its dramatic significance and cannot use their reflection for transformation through action or self-actionability. In Freire's reading, the lack of critical perception affects choice, which is illusory where it is the product of conformity (Freire 2005: 6). If it were not for the capacity to reflect on the capacity for reflection, on the world, on the human position in the world, on the human power to transform the world, literacy would not make sense (Freire 2005: 75; also see Ricoeur 1991: 60). In other words, the true meaning of learning how to read the cultures of the world only becomes apparent if it begins with where the student can see themselves as being implicated in outcomes. This is part of the reflective meaning behind the consci(enti)ousness that Markauskaite and Goodyear include in their definition of epistemic fluency (e.g. Markauskaite and Goodyear 2017: 604). This also departs from heuristic first principles with roots in classical thought.

It is not just individuals who are tasked with discerning the dramatic difference between the "ways of being, understanding, behaving, and valuing which belong to yesterday and those other ways of perceiving and valuing which announce the future" (Freire 2005: 6). Scholarship is also faced with this "tidal wave". As a result, new areas of study are emerging, such as techno- and digital anthropology, or "the interdisciplinary humanistic field that is addressing new arrangements of intellectual, social, political and economic life in the Information Age" (Davidson 2010: 206). It is noted that there is no consensus about what this latter field should be called; Donna Haraway (who continues to remain at the forefront of studies that seek epistemic fluency between the sciences and the humanities) has called it "technohumanism" (Davidson 2010: 206-7). This field acknowledges that students are bringing new skills to the college classroom and seeks to develop them through further interactive, collaborative, and participatory work (Davidson 2010: 213).

In other words, students are familiar with using the internet for multiple purposes: networked communication, knowledge-finding, etc. These skills should be made the most of in the classroom, although doing so requires "greater" professionalism and maturity on behalf of educators as it brings with it additional tasks, and additional extraneous components to keep track of (Beaty et al. 2002). These tasks include (but are not limited to) designing networked collaborations and reflective tasks that show 
practically how ideas have actionable consequences. An example of this would be to provide instructional scaffolding for students to act as content strategists and creators for a web page on a historically controversial cultural issue and periodically provide reflective prompts. A reflective prompt for the broad examples given in this paper would be to ask which model of human belonging might prove to be least destructive. Students could be provided with sample resources, instructions, and examples of tasks they would go on to do on their own, such as creating their own intertextual consideration of a dilemma or "extraneous" historical precedent. Dewey describes this type of learning as the creation of a directed as opposed to controlled environment, better than one that students would create themselves, and which has a necessary social function in societies that are becoming ever more complex (Dewey 1916: 27-8).

\section{Conclusion}

In this complex and increasingly digital atmosphere, cultural studies can redress where the "recipe principles and core knowledge" of professional praxes are not "enough" to support effective actionable professionalism. The field could depart from Markauskaite and Goodyear's definition of epistemic fluency where it is the capacity to integrate different kinds of knowledge; to coordinate different ways of knowing; to assemble an epistemic environment; to construct a consci(enti)ous self (Markauskaite and Goodyear 2017: 55, 555, 596). The always-incomplete work of learning from, coordinating, and directing environments for the (scientific and human) interrelationships through which meaning and actionability are negotiated could thus begin again. As the relational project of cultural studies implicates us in the outcome and reveals that we are responsible for our cultural readings, we can begin to talk about a consci(enti)ous inhabiting ${ }^{13}$, which includes the ability to:

... act and with senses that are fine-tuned to notice what is important, what should be cared for and what is worth doing. Constructing and/or (re)configuring one's epistemic environment are a matter of crafting affordances for both sense-making [...] and pragmatic action (Markauskaite and Goodyear 2017: 604).

It is noted that acting with senses that are fine-tuned to discern what is of value to our action and sense-making can be ultimate guiding principles. Even mechanical

\footnotetext{
${ }^{13}$ Markauskaite and Gooodyear's approach is something more than the function of alterity to provide "a space for thinking about the complexities of self and other" (Wexler in Mitchell et al. 2004) as it involves the problem of actionability, moral fields of inquiry, discussion of what constitutes professional practice, etc. (Markauskaite and Goodyear 2017: 604).
} 
physics has shown that "mind is fundamental, matter merely an illusion" (Henry 2005). The humanistic knowledges and skills cannot be forgotten in this global information age when they are implicated in science, which also relies on conceptual discourse, as seen in the introduction.

To become aware of our position in the world, to learn something responsible about the implication of literature to life and of "extraneous" fields of inquiry to the fabric of human destiny, makes good sense for cultural studies. But it remains to be seen if it is common sense.

\section{References}

Anderson, B. (1996). Imagined Communities. London and New York: Verso.

Appadurai, A. (2005). Modernity at Large. Minneapolis and London: University of Minnesota Press.

Aristotle. (1926). Aristotle in 23 Volumes, Vol. 22. Cambridge and London: Harvard University Press and William Heinemann Ltd.

Aristotle (1929). The Physics. London and New York: G. P. Putnum's Sons.

Arnold, M. (1882). Literature and Science. The Nineteenth Century, XII, 66, 216-230.

Augé, M. (1995). Non-Places: Introduction to an Anthropology of Supermodernity. London and New York: Verso.

Augé, M. (2003). Pour une anthropologie des mondes contemporains. Manchecourt: Flammarion.

Auerbach, E. (1969). Philology and 'Weltliteratur'. The Centennial Review, 13(1), $1-17$.

Bacon, F. (2008) The New Atlantis. gutenberg.org. (1 April 2019) <http://www. gutenberg.org/files/2434/2434-h/2434-h.htm>.

Bacon, F. (1902). Novum Organum. New York: P. F. Collier and Son. (1 April 2019) $<$ https://www.gutenberg.org/files/45988/45988-h/45988-h.htm>.

Bacon, F. (1913). The Advancement of Learning. London: Oxford University Press. (1 April 2019) <https://archive.org/details/baconadvancemen00bacogoog/>.

Bacon, F. (2014). The Great Instauration. Adelaide: The University of Adelaide Library. (1 April 2019) <https://ebooks.adelaide.edu.au/b/bacon/francis/instauration/>.

Bail, C. (2014). The cultural environment: measuring culture with big data. Theory and Society, 43, 3-4, 465-482.

Bakhtin, M. M. (1998). The Dialogic Imagination. Austin: University of Texas Press. Barzun, J. (1991). Begin Here: The Forgotten Conditions of Teaching and Learning. Chicago and London: The University of Chicago Press. 
Bauman, Z. (2012). Liquid Modernity. Cambridge and Malden: Polity Press.

Beaty, L. et al. (2002). Towards e-quality in networked e-learning in higher education.

Center for Studies in Advanced Learning Technology. (21 February 2018) $<$ http://csalt.lancs.ac.uk/esrc/manifesto.pdf $>$.

Boas, F. (1962). Anthropology and Modern Life. New York: W. W. Norton Company Inc. Billet, S. et al. (2017). Series Editors' Foreword. In: L. Markauskaite L. and P. Goodyear, Epistemic Fluency and Professional Education, Dordrecht: Springer, vii-viii.

Borges, J. (2013). The Library of Babel. archive.org. (1 April 2019) <https://archive. org/details/TheLibraryOfBabel>.

Brown, S. and P. Duguid (2000). The Social Life of Information. Boston: Harvard Business School Press.

Castellani, B. (2014). Brian Castellani on the Complexity Sciences. Theory, Culture \& Society. (5 April 2019) <https://www.theoryculturesociety.org/brian-castellanion-the-complexity-sciences/>.

Castellani, B. (2018). Map of the Complexity Sciences. Art \& Science Factory. (5 April 2019) <https://www.art-sciencefactory.com/complexity-map_feb09.html>.

Cicero. (1954). Rhetorica ad Herennium, trans. by Harry Caplan. Cambridge, MA: Harvard University Press.

Clifford, J. (1988). The Predicament of Culture. Cambridge: Harvard University Press. Davenport, G. (2005). The Geography of the Imagination. Boston: Nonpareil Books.

Davidson, C. N. (2010). Humanities and Technology in the Information Age. In: R.

Frodeman (ed.), Oxford Handbook of Interdisciplinarity, Oxford and New York:

Oxford University Press, 206-9.

Deleuze, G. and R. Krauss (1983). Plato and the Simulacrum. October, 27, 45-56.

Dewey, J. (1920). The Child and the Curriculum. Chicago: Chicago University Press.

Dewey, J. (1916). Democracy and Education. New York: The Macmillan Company.

Dewey, J. (1946). Problems of Men. New York: Philosophical Library.

Drucker, P. (1967). The Effective Executive. New York: Harper \& Row, Publishers, Inc.

Executive Office of the President. (2014). Big Data: Seizing Opportunities,

Preserving Values. Obamawhitehouse.archives.gov. (15 October 2019) <https:// obamawhitehouse.archives.gov/sites/default/files/docs/big_data_privacy_ report_may_1_2014.pdf $>$.

Fernández, A. T. (2009). La Biblioteca de Babel: Una modesta propuesta. Casa del tiempo, 2(24), 77-80. (25 June 2018) <http://www.uam.mx/difusion/ casadeltiempo/24_iv_oct_2009/casa_del_tiempo_eIV_num24_77_80.pdf $>$.

Foucault, M. (2002). The Archaeology of Knowledge. London and New York: Routledge. 
Freire, P. (2005). Education for Critical Consciousness. London and New York: Continuum.

Gadamer, H. (2004). Truth and Method. London and New York: Continuum.

Geertz, C. (1973). The Interpretation of Cultures. New York: Basic Books.

Giroux, H. (2014). Neoliberalism's War on Education. Chicago: Haymarket Books.

Giroux, H. (1983). Theory and Resistance. Masachussettes: Bergin \& Garvey Publishers, Inc.

Goetz, G. (2009). Nikolaj Velimirović's Views on Literature. Unpublished master's thesis. Faculty of Philology, Belgrade University.

Gould, S. J. (2003). Hedgehog, the Fox, and the Magister's Pox. New York: Harmony. Hadot, P. (2006). The Veil of Isis. Cambridge and London: Harvard University Press.

Haidt, J. (2006). The Happiness Hypothesis: Finding Modern Truth in Ancient Wisdom. New York: Basic Books.

Haisch, B. (2014). Is the Universe a Vast Computer-Created Virtual Reality Simulation. Cosmos and History: The Journal of Natural and Social Philosophy, 10(1), 49-61.

Heidegger, M. (1962). Being and Time, trans. by J. Macquarrie and E. Robinson. Blackwell: Oxford.

Heidegger, M. (1949). The Question Concerning Technology. Paper delivered in Bremen, 1 December 1949. (6 August 2012) <http://www.english.hawaii.edu/ criticalink/heidegger/guide1.html $>$.

Hendrickson, C. et al. (2018). Countering the Geography of Discontent: Strategies For Left-Behind Places. Brookings. (3 April 2019) <https://www.brookings. edu/wp-content/uploads/2018/11/2018.11_Report_Countering-geography-ofdiscontent_Hendrickson-Muro-Galston.pdf $>$.

Henry, R. (2005). The Mental Universe. Nature, 436, 29.

Huxley, T. (1888). Science and Culture and Other Essays. New York: D. Appleton and Company.

Jackson, D. and J. Temperley (2007). From Professional Learning Community to Networked Learning Community. In: L. Stoll L and K. Seashore Louis (eds.), Professional Learning Communities: Divergence, Depth, and Dilemmas, Maidenhead, UK: McGraw Hill and Open University Press, 45-62.

Kreiss, D. and S. McGregor (2019). The 'Arbiters of What Our Voters See': Facebook and Google's Struggle with the Policy, Process, and Enforcement Around Political Advertising. Political Communication. (1 July 2019) <https://www. tandfonline.com/doi/full/10.1080/10584609.2019.1619639>.

Kristeva, J. (1988). L'étrangers à nous-mêmes. Paris: Librairie Arthème Fayard.

Markauskaite, L. and P. Goodyear (2017). Epistemic Fluency and Professional Education: Innovation, Knowledgeable Action and Actionable Knowledge. Dordrecht: Springer. 
Kroeber, A. (1949). An Authoritarian Panacea. American Anthropologist, 51(2), 318 320.

Michalski, M. (2005). Hermeneutic Phenomenology as Philology. In: D. Gross and A. Kammann (eds.), Heidegger and Rhetoric, New York: State University of New York Press, 65-80.

Mitchell, W. J. T. et al. (eds.) (2014). Theories of Media: Keywords Glossary. Chicago: University of Chicago. (1 February 2019) <http://csmt.uchicago.edu/ glossary2004/navigation.htm>.

Munger, C. (2011). Poor Charlie's Almanack. Virginia Beach, VA: PCA Publication, LLC.

Myers, D.G. (1994). On the Teaching of Literary Theory. Philosophy and Literature, 18(2), 326-336.

Nagel, T. (2012). Mind and Cosmos. New York: Oxford University Press.

Nietzsche, F. (2010). On the Use and Abuse of History for Life. Wikisource. (15 March 2019) $<$ https://en.wikisource.org/wiki/On_the_Use_and_Abuse_of_History_ for Life>.

Nguyen, $\bar{C}$. T. (2018). Echo Chambers and Epistemic Bubbles. Episteme. (21 June 2018) <https://doi.org/10.1017/epi.2018.32>.

Odell, J. (2018). Designing for the In-Between: Hybrids, 1990s Art, and A Giant Floating Worm. Medium. (20 March 2019) <https://medium.com/s/world-wide$\mathrm{wtf} /$ designing-for-the-in-between-hybrids-1990s-net-art-and-a-giant-floatingworm-34be64b872d3>.

Piaget, J. (1948). The Moral Judgment of the Child. Glencoe, Illinois: The Free Press. Plato. Gorgias. In: W.R.M. Lamb (trans.), Plato in Twelve Volumes, Vol. 1, Cambridge, MA: Harvard University Press.

Plato. (1966). Phaedo. In: W. R. M. Lamb (trans.), Plato in Twelve Volumes, Vol. 1, Cambridge, MA: Harvard University Press.

Pound, E. (1960). The ABC of Reading. New York: New Directions.

Randall, J. H. (1967). Plato's Treatment of the Theme of the Good Life and His Criticism of the Spartican Ideal. Journal of the History of Ideas, 28(3), 307-324.

Raymond, E. (2000). The Cathedral and the Bazaar. Catb.org. (28 September 2019) $<$ http://www.catb.org/ esr/writings/cathedral-bazaar/cathedral-bazaar/index. html>.

Rheingold, H. (1980s). Tools for Thought. (28 September 2019)<http://www.rheingold. com/texts/tft/index.html\#index $>$.

Ricoeur, P. (1991). A Ricoeur Reader: Reflection and Imagination. Toronto and Buffalo: University of Toronto Press.

Schäfer, W. (1995). The Global Ages. Stoneybrook.edu. (15 January 2019) <https:// www.stonybrook.edu/globalhistory/age.html>. 
Sholler, D. et al. (2019). Ten Simple Rules For Helping Newcomers Become Contributors To Open Projects. PLoSComput Biol 15(9). PLoS.org. (28 September 2019) <https://doi.org/10.1371/journal.pcbi.1007296>.

Snow, C.P. (1959). The Two Cultures and the Scientific Revolution. New York: Cambridge University Press.

Snyder, L. J. (2011). The Philosophical Breakfast Club. New York: Random House Inc.

Spolsky. J. (2019). Joel on Software. joelonsoftware.com. (5 December 2019) <https:// www.joelonsoftware.com/author/joelonsoftware/s.

Stiegler, B. (2013). What Makes Life Worth Living: On Pharmacology. Cambridge: Polity Press.

Stoller, M. (2019). WeWork and Counterfeit Capitalism. mattstoler.substack.com. (27 September 2019) <https://mattstoller.substack.com/p/wework-and-counterfeitcapitalism>.

Taylor, F. (1919). The Principles of Scientific Management. New York and London: Harper \& Brothers Publishers.

Taussig, M. (1992). The Nervous System. New York: Routledge.

The GoodWork Toolkit. 2017. Harvard Graduate School of Education. (1 February 2019) <thegoodproject.org/toolkits-curricula/the-goodwork-toolkit/>.

Todorova, M. (1997). Imagining the Balkans. New York and Oxford: Oxford University Press.

Trilling, L. (1961). On the Modern Element in Modern Literature. Partisan Review, 28(1), 9-35. (1 April 2019) <http://archives.bu.edu/collections/partisan-review/ search/detail?id $=326052>$.

Velimirović, N. (2001). Sabrana dela, $V$. Linc: Pravoslavna crkvena opština.

Vico, G. (1976). On the Heroic Mind. Social Research, 43(4), 886-903.

Vygotsky, L. (1979). Mind in Society: The Development of Higher Psychological Processes. Cambridge and London: Harvard University Press.

Zuboff, S. (2019). The Age of Surveillance Capitalism: The Fight for a Human Future at the New Frontier of Power. New York: Public Affairs. 